\title{
Optimization of various factors affecting Agrobacterium-mediated transformation and regeneration of putative transgenic Malaysian MR219 rice with Bacillus SP 289 endo- $\beta-1,3-1,4-$ glucanase gene
}

\author{
Zuraida Ab Rahman ${ }^{1 *}$, Noriha Mat Amin', Mohd Yusof Nor Rahim¹, Azlinda Erny Yunus', \\ Rohaiza Ahmad Redzuan', Muhamad Ridzuan Rashid', Asfaliza Ramli², Ayu Nazreena Othman', \\ Marzukhi Hashim 1 , Rahiniza Kamaruzaman², Sreeramanan Subramaniam ${ }^{3}$
}

${ }^{1}$ Biotechnology \& Nanotechnology Research Centre, MARDI Headquarters, MARDI HQ, Persiaran MARDI-UPM, 43400 Serdang, Selangor, Malaysia, ${ }^{2}$ Rice Industry Crop Centre, MARDI Headquarters, Research Centre, MARDI Headquarters, MARDI HQ, Persiaran MARDI-UPM, 43400 Serdang Selangor, Malaysia, ${ }^{3}$ School of Biological Sciences, Universiti Sains Malaysia, Georgetown, 11800 Penang, Malaysia

\section{A B S T R A C T}

\begin{abstract}
Sheath blight disease caused by Rhizoctonia solani is the most destructive diseases in rice cultivation. Development of transgenic indica rice MR219 through Agrobacterium tumefaciens strain EHA 105 harbouring the plasmid pCAMBIA 1305.2 with endo-beta-1,3-1,4-glucanase gene from Bacillus SP 289 is one of the strategies to engineer disease resistance. Four optimisation parameters were examined such as Agrobacterium culture cell density ( 0.1 to 1.0 based on $\mathrm{OD}_{600 \mathrm{~nm}}$ ), callus immersion time in the Agrobacterium culture ( 30 to 120 minutes), duration of the subsequent drying time (15 to 120 minutes) and co-cultivation period ( 1 to 6 days). Hygromycin-resistant embryogenic calli developed after 8 to 10 weeks of transformation. Improved transformation rates were achieved when calli were incubated with an Agrobacterium suspension with a culture density of $\mathrm{OD}_{600 \mathrm{~nm}} 0.2$ for 30 mins, followed by 90 mins of drying time and co-cultivation for 3 days. PCR analysis of the transformants confirmed the presence of Bacillus SP 289 endo-beta-1,3-1,4-glucanase and hpt genes in the rice genome. The transgenic rice plants obtained in this study will be tested against sheath blight disease.
\end{abstract}

Keywords: Malaysian MR219; Agrobacterium tumefaciens; Bacillus SP 289; endo-beta-1,3-1,4-glucanase

\section{INTRODUCTION}

Rhiroctonia solani caused sheath blight disease in rice is one of the most widely distributed diseases globally. Crop losses may range from slight to heavy each year, depending on prevailing weather conditions, the stage of plant growth when infection occurs, the extent of infection, and the rice variety grown.

In recent years, resistant rice cultivars to Rbiroctonia solani have been developed by inserting chitinase genes into the rice plant genome. Previously, Datta et al. (2001) demonstrated production of fungal resistant rice cultivars with a rice chitinase gene (RC7) obtained in R. solaniinfected rice plants. Similarly, Kumar et al. (2003) reported on the successful production of $R$. solani-resistant rice with different type of rice chitinase gene (chi11). In addition, higher number of research reports on the use of glucanase gene in transgenic research for the development of fungal resistant rice plants. Nishizawa et al. (2003) introduced $\beta-1,3$ and 1,4-glucanase gene $(G n s 1)$ in rice in order to increase fungal disease resistance. To attain an even higher degree of disease resistance, therefore multiple genes of fungal walldegrading enzymes (chitinase, glucanase and thaumatin-like proteins) were co-expressed in transgenic rice. For example, Mei et al. (2004) have introduced an ech42 gene encoding endochitinase, the nag70 gene encoding exochitinase and the gluc78 gene encoding glucanase into rice. Finally, transgenic rice plants displayed a superior resistance against sheath blight disease were successfully obtained.

\footnotetext{
${ }^{*}$ Corresponding author:

Zuraida Ab Rahman, Biotechnology \& Nanotechnology Research Centre, MARDI Headquarters, MARDI HQ, Persiaran MARDI-UPM, 43400 Serdang, Selangor, Malaysia. E-mail: azuraida@mardi.gov.my

Received: 03 March 2017; Revised: 30 September 2017; Accepted: 01 October 2017; Published Online: 11 October 2017
} 
Transgenic plant technology provides an avenue for genetic manipulation of rice to enhance its agronomic performance by increasing resistance to biotic and abiotic stresses (Sahrawat et al., 2003). Even though various methods have been employed to introduce cloned DNA sequences into the rice plant, however Agrobacterium tumefaciens-mediated system is still preferable method since it possesses several advantages over other systems. These include the ability to transfer large segments of DNA with precise insertion of transgenes resulting in fewer copies of inserted genes at lower cost (Smith and Hood, 1995; Dai et al., 2001).

In the present work, an endo- $\beta-1,3-1,4-$ glucanase gene has been introduced from locally isolated rhizosphere soil bacteria, Bacillus SP 289 into embryogenic calli of indica rice MR219 using Agrobacterium-mediated transformation system. The aim of this study was to produce MR219 rice plants against sheath blight disease. The effects of four experimental variables, namely Agrobacterium culture cell density, immersion time, duration of the subsequent drying time, and co-cultivation period were examined in order to optimise the transformation system.

\section{MATERIALS AND METHODS}

\section{Plant materials and explants}

Embryogenic calli used derived from the dough stage of rice seeds. The seeds were dehusked, cleaned and sterilized by immersion in 100\% ethanol for 1-2 min, followed by immersion in 100\% Clorox (sodium hypochlorite 5.25\%) supplemented with a few drops of Tween-20 for $30 \mathrm{~min}$. After rinsing few times with sterile distilled water, the seeds were introduced on callus induction Murashige and Skoog (MS) medium (Murashige and Skoog 1962) with $30 \mathrm{~g} / \mathrm{L}$ sucrose, $10 \mathrm{mg} / \mathrm{L}$ glucose, $0.3 \%$ Gelrite agar, $10 \mathrm{mg} / \mathrm{L}$ naphthaleneacetic acid and $1 \mathrm{mg} / \mathrm{L}$ 2,4-D (Zuraida et al., 2010). Cultured seeds maintained in the dark condition at $25-27^{\circ} \mathrm{C}$ under cool. Six week-old embryogenic calli were used for the transformation of indica rice MR219.

\section{Agrobacterium strain and plasmid}

A. tumefaciens strain EHA 105 was used in genetic transformation. The bacterium harboured the plasmid pCAMBIA 1305.2 (http://www.cambia.org.au/) with the endo-beta-1,3-1,4-glucanase gene driven by the Cauliflower Mosaic Virus 35S promoter (CaMV35S) and nopaline synthase (NOS) terminator. This vector had hygromycin phosphotransferase $(h p t)$ gene in the T- DNA region driven by a double-enhancer version of the CaMV35S promoter and terminated by the CaMV35S polyA signal which conferred resistance to the antibiotic hygromycin used as a transformation selection marker (Fig. 1).

\section{Evaluation of experimental variables influencing transformation efficiency}

Several factors affecting the Agrobacterium-mediated transformation frequency in MR219 callus were evaluated. The factors were such as Agrobacterium culture cell density $\left(0.1,0.2,0.4,0.6,0.8\right.$ and $\left.1.0 \mathrm{OD}_{600 \mathrm{~nm}}\right)$, callus immersion time in Agrobacterium culture (30, 60, 90 and 120 minutes), subsequent duration of drying before co-cultivation $(15,30$, 45, 60 and 90 minutes), and co-cultivation period (1, 2, 3, 4, 5 and 6 days).To determine the optimum conditions for transformation, one factor of the standard conditions was changed each time. The transformed calli were transferred to a pre-regeneration medium (Zuraida et al., 2010) supplemented with $100 \mathrm{mg} / \mathrm{L}$ carbenicillin, $100 \mathrm{mg} / \mathrm{L}$ cefotaxine and $50 \mathrm{mg} / \mathrm{L}$ hygromycin as a selective agent. Transformed calli were incubated in dark condition at $27 \pm 1^{\circ} \mathrm{C}$, and were then sub-cultured at 2 -week intervals on the same medium for the selection process.

\section{Regeneration of transgenic rice plants}

The transformed whitish embryos were transferred to MS regeneration media (Zuraida et al. 2011) supplemented with $30 \mathrm{mg} / \mathrm{L}$ hygromycin B, $100 \mathrm{mg} / \mathrm{L}$ carbenicillin and $100 \mathrm{mg} / \mathrm{L}$ cefotaxine for further regeneration. The cultures were then kept at $26 \pm 2{ }^{\circ} \mathrm{C}$ under 16 -h photoperiod. Total number of regenerated plants was determined after 4 to 8 weeks. The percentage of plant regeneration was worked out as follows:

Plant regeneration response $(\%)=$ Total number of confirmed transformants callus/Total number of calluses x 100 .

Putative regenerated plantlets with good shoot and root growth were taken out for hardening. The plantlets were

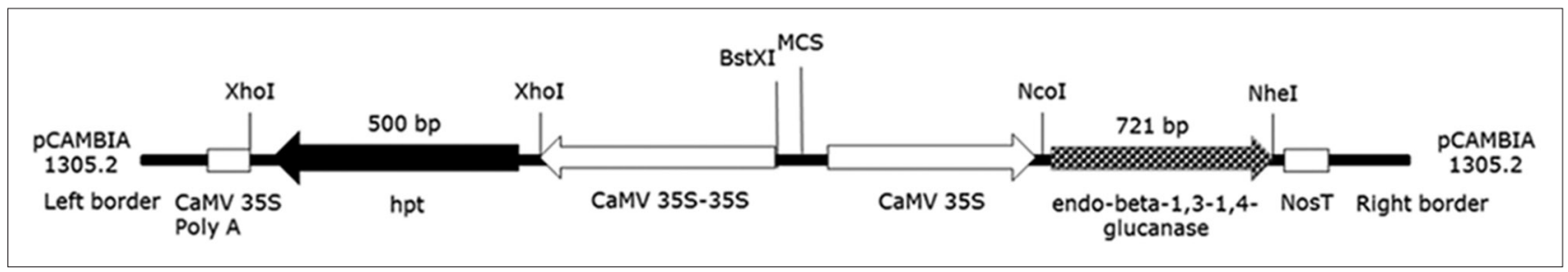

Fig 1. Schematic diagram of the plasmid pCAMBIA1305.2 and T-DNA construct. 
washed repeatedly to remove adhering agar and kept in vermiculate for under culture conditions. Plantlets were then transferred into small plastic cups containing autoclaved mix soil and vermiculate (20:80) covered with plastic bags. For two weeks, plantlets were allowed to be under culture conditions. Polybags were removed and plantlets were transferred to mud pots then transferred to the transgenic glass house for further maturity.

\section{PCR analysis of transgenic plants}

To confirm the presence of the endo-beta-1,3-1,4-glucanase gene in transgenic rice plants, DNA was isolated from $0.5 \mathrm{~g}$ of fresh young leaves using DNeasy Plant Mini Kit (QIAGEN, Germany). For the PCR analysis, $400 \mathrm{ng}$ of plant genomic DNA or $50 \mathrm{ng}$ of plasmid DNA were used in $25 \mu \mathrm{L}$ reaction mixure. The primers designed to amplify 720-bp fragments of endo-beta-1,3-1,4-glucanase gene at $55^{\circ} \mathrm{C}$

(F 5'-CTAATTCTTGTCACTGGATTGTTTTTG-3'; R 5'GTATAGCGGATTTACACCATTGTAGG-3') and 508-bp fragments of hpt gene at $50^{\circ} \mathrm{C}(\mathrm{F}$ 5'-ATGAAAAAGCCTGAACTCACCGCGA-3'; R 5’TCCATCACAGT'T'TGCCAGTGATACA-3').

Amplification was performed in a PTC-200 ${ }^{\mathrm{TM}}$ Programmable Thermal Controller (MJ Research, Inc., USA). The PCR program profile for both genes was as follows; initial denaturation at $95^{\circ} \mathrm{C}$ for $3 \mathrm{~min}$, followed by 35 cycles of $94{ }^{\circ} \mathrm{C}$ for $30 \mathrm{sec}, 45 \mathrm{sec}$ at the annealing temperature of each gene and $1 \mathrm{~min}$ at $72{ }^{\circ} \mathrm{C}$, with a final extension at $72{ }^{\circ} \mathrm{C}$ for $10 \mathrm{~min}$. The amplified products were separated on $1 \%$ agarose gel and visualized by staining with ethidium bromide.

\section{Statistical analysis}

Total of 100 embryogenic callus samples used in each experiment and were repeated two times. Statistical analysis was performed using one-way analysis of variance (ANOVA) followed by Duncan's test to determine significant $(\mathrm{P} \leq 0.05)$ differences. $\mathrm{P}$ value of less than 0.05 was considered as significant.

\section{RESULTS AND DISCUSSION}

Using an appropriate Agrobacterium cell density is critical to successful genetic transformation. An optimal density $0.1-0.2$ was found to be optimal for the survival of the explants after immersion in the bacterium medium for 30 minutes. Increasing bacterium concentrations $(>0.2$ $\left.\mathrm{OD}_{600 \mathrm{~nm}}\right)$ resulted in a significant decrease in the number of hygromycin-resistant embryogenic calli obtained (Fig. 2).

Hg-resistant embryogenic calli were obtained between eight and ten weeks after selection process (Fig. 3 a,b). Moreover,

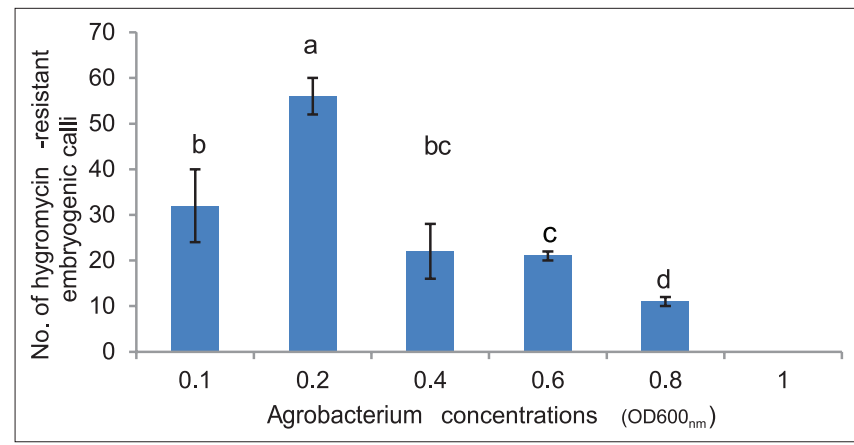

Fig 2. Effect of Agrobacterium culture cell density $\left(O D_{600 \mathrm{~nm}}\right)$ on the production hygromycin-resistant embryogenic calli of indica rice.

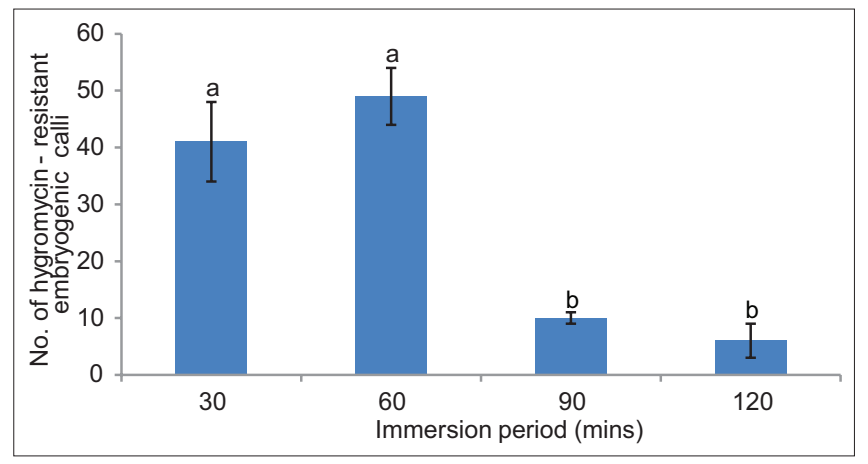

Fig 3. Effect of immersion time on the production hygromycin-resistant embryogenic calli after transformation of indica rice.

no transformed calli were obtained when bacterium cell densities used at $1.0 \mathrm{OD}_{600 \mathrm{~nm}}$ and untransformed calli (Fig. 3c). This result was contrast to Sreeramanan et al. (2009), who reported that low transformation efficiency with Agrobacterium at a cell density of 0.2 at $\mathrm{OD}_{600 \mathrm{~nm}}$ was attributed due to lack of sufficient Agrobacterium cells to transfer T-DNA into orchid cells. According to Zuraida et al. (2011), delivery of gus $A$ gene was most efficient in rice cultivar MR232 by using Agrobacterium cell density of $\mathrm{OD}_{600 \mathrm{~nm}} 0.6$. Yong et al. (2006) reported that the highest rate of genetic transformation of members of the Melastomataceae family with Agrobacterium LBA4404 was obtained at a cell density of $0.8 \mathrm{OD}_{600 \mathrm{~mm}}\left(1 \times 10^{7} \mathrm{cfu} \mathrm{m}^{-1}\right)$. They also found that higher concentrations decreased transformation efficiency for shoot and node explants. With Vanda Kasem's Delight (VKD) orchid, Agrobacterium suspension culture at $0.8 \mathrm{OD}_{600 \mathrm{~nm}}$ produced highest production $(91.6 \%)$ of GUS positive explants, followed by $0.6 \mathrm{OD}_{600 \mathrm{~nm}}(60 \%)$ and $0.4 \mathrm{OD}_{600 \mathrm{~nm}}$ $(51.6 \%)$ (Pavallekoodi et al., 2014).

Differences in the production hygromycin-resistant embryogenic calli after transformation event were observed for each level of bacterial density. Calli immersed for $60 \mathrm{~min}$ in Agrobacterium culture $\left(0.2 \mathrm{OD}_{600}\right)$ produced the most hygromycin-resistant embryogenic calli (Fig. 4). This immersion or infection period allowed sufficient time for 
the infection process leading to transformation in the calli, whereas longer immersion periods were not helpful. Pavallekoodi et al. (2014) indicated that a 30-minute immersion period in Agrobacterium culture was the optimum for transforming $V$ anda orchids, with immersion

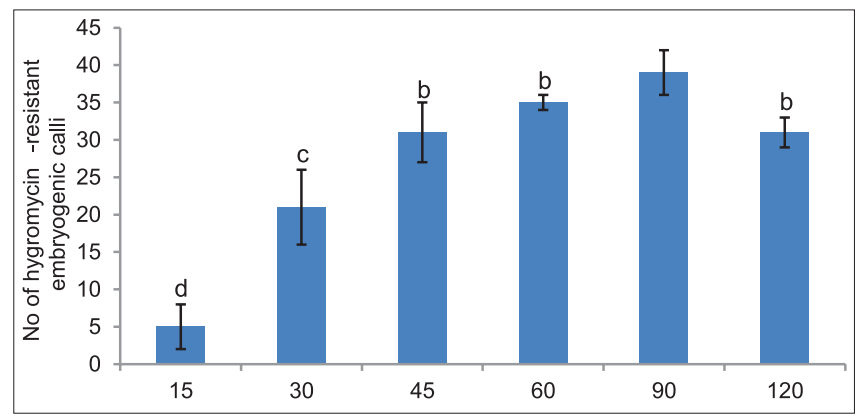

Fig 4. Effect of the drying period following infection (min) on the production hygromycin-resistant embryogenic calli of indica rice.

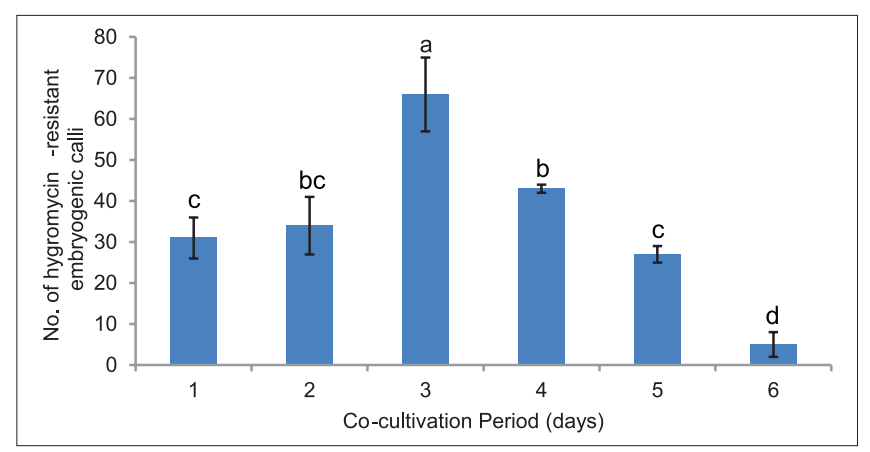

Fig 5. Effect of co-cultivation periods on the production hygromycinresistant embryogenic calli of indica rice. durations of 10 to 20 min being less effective. According to Orlikowska et al. (1995), increased bacterial infectivity at longer duration time may lead to hypersensitive response and causes reduction of regeneration frequency.

The effect of the drying period of calli after infected with Agrobacterium is summarized in Fig. 5. The highest number of hygromycin-resistant embryogenic calli was obtained with calli drying for 90 minutes followed by 60 minutes on sterile filter paper prior to co-cultivation. A. tumefaciens required specific time period for attachment and maximum transfer of T-DNA to the explants. Even though shorter infection period would produce low numbers of transformed explants, but an excessive period resulted hypertonic conditions in the cells that causes to rupture. Alternatively, hyper-activation of defense mechanisms induced in the cells could lead to lethality (Mannan et al., 2009). A co-cultivation incubation period of 3 days was found suitable for the transfer of TDNA into the indica rice calli (Fig. 6).These results are in accordance with Mannan et al. (2009), who reported that co-cultivation with Agrobacterium for a period of 3 to 4 days gave maximum positive GUS expression in Artemisia absinthium regenerated plantlets.

The duration of co-cultivation of cell cultures with Agrobacterium had an important influence on transformation efficiency. In this study, the co-cultivation period of the rice calli with Agrobacterium was optimal at 3 days. In comparison, the number of Arabidopsis transformed calli increased with co-cultivation time, reaching an optimum
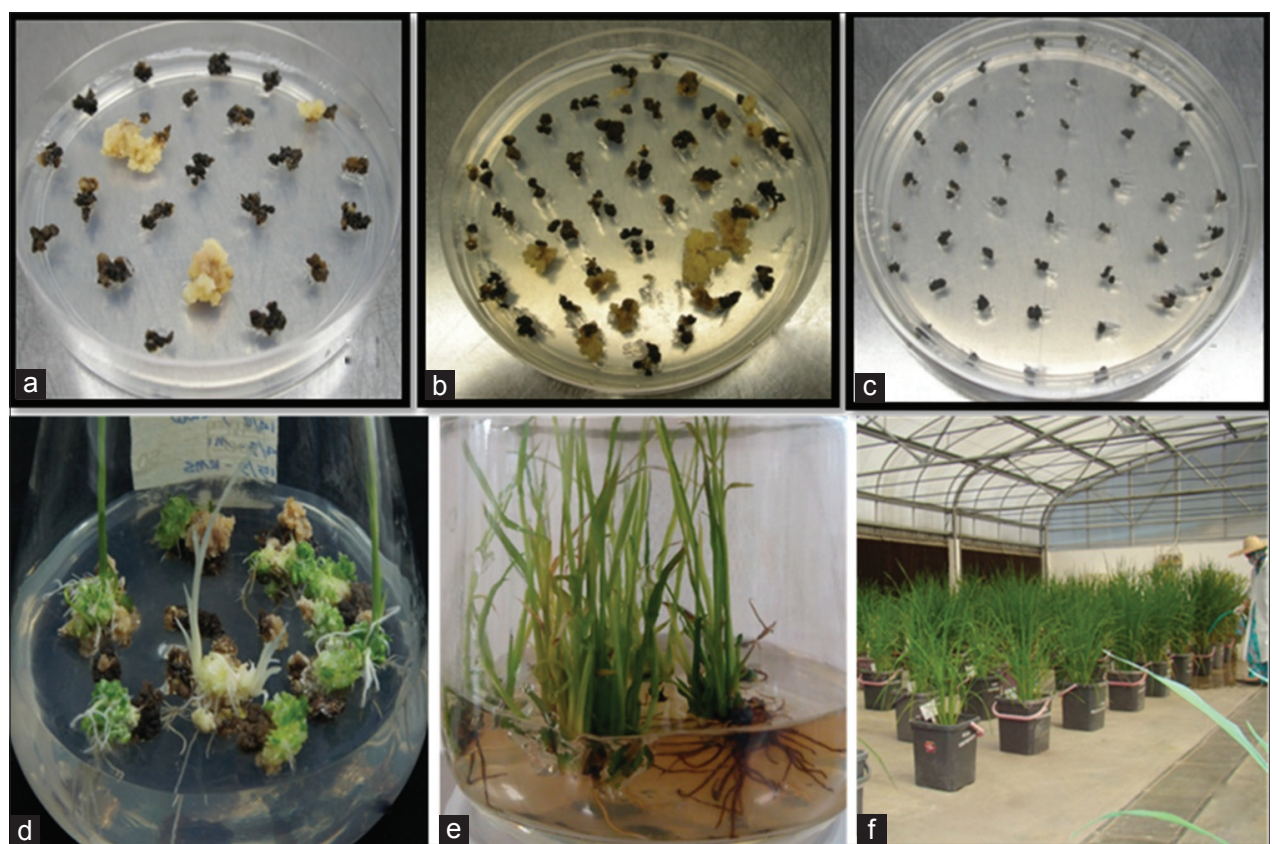

Fig 6. Production of transgenic MR219 rice plants with Bacillus SP 289 endo-beta-1,3-1,4-glucanasegene using Agrobacterium-mediated transformation. Development of hygromycin-resistant embryogenic calli ( $a$ and $b$ ) after eight to ten weeks of transformation. Untransformed control calli did not show further development (c). Regenerated shoots (d) and emerging plantlets (e), plant in transgenic glass house (f). 


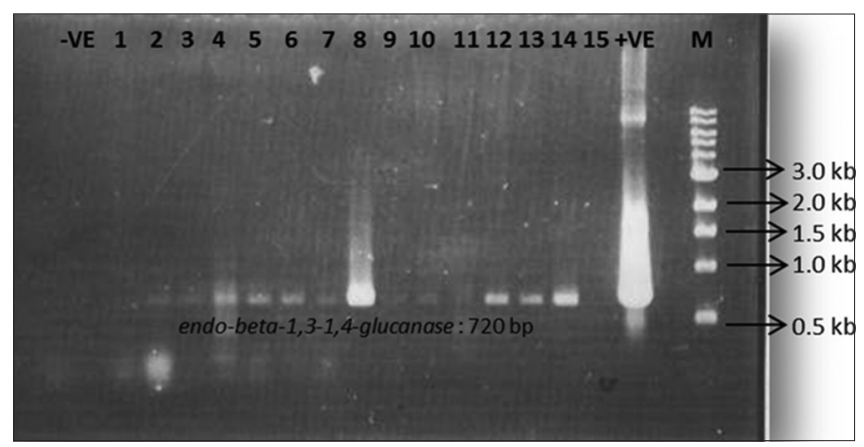

Fig 7. PCR amplification of endo-beta-1,3-1,4-glucanase gene from transgenic $R_{0}$ lines transformed with the gene construct; -VE: Negative control, Lane 1-15: Transgenic lines 1-15, +VE: Positive control, M: $1 \mathrm{~kb}$ DNA Ladder (New England Biolabs, USA)

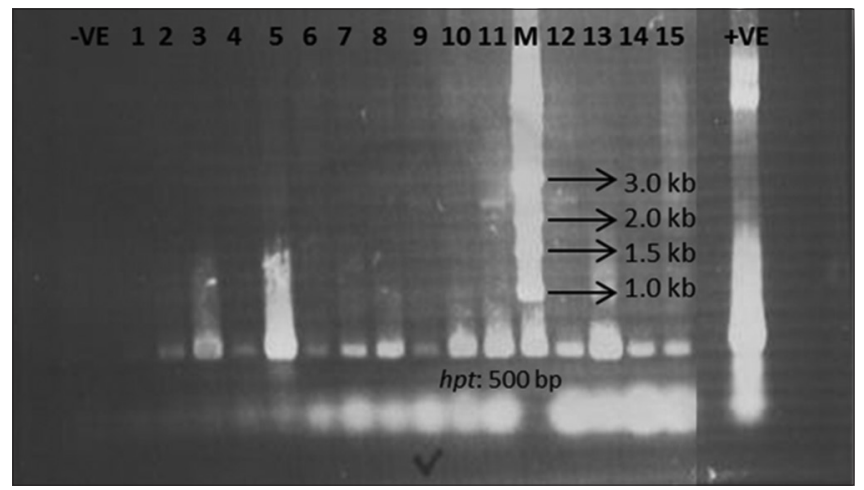

Fig 8. PCR amplification of hygromycin phosphotransferase gene (hpt) from transgenic $R_{0}$ lines transformed with the construct; -VE: Negative control, Lane 1-15: Transgenic lines 1-15, +VE: Positive control, M: $1 \mathrm{~kb}$ DNA Ladder (New England Biolabs, USA)

after 48 hours and longer co-cultivation time eventually reduced viability of the plant cells and delay in the growth of transformed explants (Christoph et al., 1997). Similarly, Vergauwe et al. (1998) obtained the best results after cocultivating Artemisia annua with Agrobacterium for 2 to 3 days. They also noticed that a longer co-cultivation period did not improved transformation efficiency.

Transformed somatic embryos proliferate more actively and have minimal browning (Fig. 3d). Regenerated shoots with root were then transferred into free-hg media (Fig. 3e) before brought to the transgenic glasshouse for further development (Fig. 3f). Integration of transgenes in the genome of putative transformants was determined by PCR analysis of the $\mathrm{R}_{0}$ rice plants. Amplified product of 720 bp DNA fragment for endo-beta-1,3-1,4-glucanase gene was obtained from 12 lines and a 500 bp DNA fragment for $h p t$ gene was obtained for 14 lines of the MR 219 rice plants, respectively (Figs. 7 and 8).

Hence, these findings suggest that the Bacillus SP 289 endo-beta-1,3-1,4-glucanase gene could be utilized as a genetic source of disease resistance against sheath blight.

\section{ACKNOWLEDGEMENTS}

This research was supported by MOSTI grant (07-03-08PB013).

\section{Author contributions}

Zuraida Ab Rahman: designed and carried out the experiments, provided the materials and ideas for the study. Wrote the article; Noriha Mat Amin: Conducted field analysis, designed and carried out the experiments, Wrote the article; Mohd Yusof Nor Rahim: Conducted field analysis; Azlinda Erny Yunus: Conducted field analysis. Rohaiza Ahmad Redzuan: Conducted field analysis; Muhamad Ridzuan Rashid: Conducted field analysis; Asfaliza Ramli : provided the materials and ideas for the study. Ayu Nazreena Othman: designed and carried out the experiments, Marzukhi Hashim: provided the materials and ideas for the study. Rahiniza Kamaruzaman: provided the materials and ideas for the study. Sreeramanan Subramaniam: Wrote the article

\section{REFERENCES}

Christoph, F., K. Marc and N. Lutz. 1997. Stable transformation of an Arabidopsis cell suspension culture with firefly luciferase providing a cellular system for analysis of chaperone activity in vivo. Plant Cell. 9: 2171-2181.

Dai, S. H., P. Zheng, P. Marmey, S. P. Zhang, W. Z. Tian, S. Y. Chen, R. N. Beachy and C. Fauquet. 2001. Comparative analysis of transgenic plants obtained by Agrobacterium-mediated transformation and particle bombardment. Mol. Breed. 7: 25-33.

Datta, K., J. Tu, N. Oliva, I. Ona, R. Velazhahan, T. W. Mew, S. Muthukrishnan and S. K. Datta. 2001. Enhanced resistance to sheath blight by constitutive expression of infection-related rice chitinase in transgenic Elite Indica rice cultivars. Plant Sci. 160: 405-414.

Kumar, K. K., K. Poovannan, R. Nandakumar, K. Thamilarasi, C. Geetha, N. Jayashree, E. Kokiladevi, J. A. J. Raja, R. Samiyappan, D. Sudhakar and P. Balasubramanian. 2003. A high throughput functional expression assay system for a defense gene conferring transgenic resistance on rice against the sheath blight pathogen, Rhizoctonia solani. Plant Sci. 165: 969-976.

Mannan, A., N. S. Tooba and M. Bushra. 2009. Factors affecting Agrobacterium tumefaciens mediated transformation of Artemisia absinthium L. Pak. J. Bot. 41(6): 3239-3246.

Mei, L., S. Zong-Xiu, Z. Jei, X. Tong, E. H. Gary and L. Matteo. 2004. Enhancing rice resistance to fungal pathogens by transformation with cell degrading enzyme genes from Trichoderma atroviride. J Zhejiang Univ. Sci. 5: 133-136.

Murashige, T. and F. Skoog. 1962. A revised medium for rapid growth and bioassays with tobacco tissue culture. Physiol. Plant. 15: 473-497.

Nishizawa, Y., M. Saruta, K. Nakazono, Z. Nishio, M. Soma, T. Yoshida, E. Nakajima and T. Hibi. 2003. Characterization of transgenic rice plants over-expressing the stress-inducible b-glucanase gene Gns1. Plant Mol. Biol. 51: 143-152.

Orlikowska, T. K., H. J. Cranston and W. E. Dyer. 1995. Factors 
influencing Agrobacterium tumefaciens-mediated transformation and regeneration of the safflower cultivar 'centennial". Plant Cell. Tissue Organ. Cult. 40(1): 85-91.

Pavallekoodi, G., J. J. A. Jessica, U. Jasim and S. Sreeramanan. 2014. Agrobacterium-mediated transformation of the recalcitrant Vanda kasem's delight orchid with higher efficiency. Sci. World J. 2014: Article ID: 583934, 10.

Sahrawat, A. K., D. Becker, S. Lutticke and H. Lorz. 2003. Genetic improvement of wheat via alien gene transfer an assessment. Plant Sci. 165: 1147-1168.

Smith, R. H. and E. H. Hood. 1995. Agrobacterium tumefaciens transformation of monocotyledons. Crop Sci. 35: 301-309.

Sreeramanan, S., M. R. Samian, Midrarullah and R. Xavier. 2009. Preliminary factors influencing transient expression of gusA in Dendrobium savin white protocorm-like bodies (PLBs) using Agrobacterium-mediated transformation system. World Appl. Sci. J. 7(10): 1295-1307.
Vergauwe, A., E. Van Geldre, D. Inze, M. Van Montagu and E. Van den Eeckhout. 1998. Factors influencing Agrobacterium tumefaciens-mediated transformation of Artemisia annua L. Plant Cell. Rep. 18: 105-110.

Yong, W. T. L., O. A. Janna and M. Maziah. 2006. Optimization of Agrobacterium-mediated transformation parameters for Melastomataceae spp. using green fluorescent protein (GFP) as a reporter. Sci. Hortic. 109(1): 78-85.

Zuraida, A. R., R. Suri, W. S. Wan Zaliha and S. Sreeramanan. 2010. Regeneration of Malaysian Indica rice (Oryza sativa) variety MR232 via optimised somatic embryogenesis system. J. Phytol. 2(3): 30-38.

Zuraida, A. R., A. S. Zulkifli, B. Naziah, L. J. Advina, Z. Zamri and S. Sreeramanan. 2011. Preliminary investigations of Agrobacterium-mediated transformation in Indica rice MR219 embryogenic callus using gusA gene. Afr. J. Biotechnol. 10(40): 7805-7813. 